Article

\title{
In Vitro Activity of Ibrexafungerp against a Collection of Clinical Isolates of Aspergillus, Including Cryptic Species and Cyp51A Mutants, Using EUCAST and CLSI Methodologies
}

\author{
Olga Rivero-Menendez ${ }^{1}$, Juan Carlos Soto-Debran ${ }^{1}$, Manuel Cuenca-Estrella ${ }^{1,2}$ \\ and Ana Alastruey-Izquierdo 1,2,*iD \\ 1 National Centre for Microbiology, Mycology Reference Laboratory, Instituto de Salud Carlos III, \\ 28222 Madrid, Spain; olgariveromenendez@gmail.com (O.R.-M.); juanc.soto@isciii.es (J.C.S.-D.); \\ mcuenca-estrella@isciii.es (M.C.-E.) \\ 2 Spanish Network for Research in Infectious Diseases (REIPI RD16/CIII/0004/0003), Instituto de Salud \\ Carlos III, 28222 Madrid, Spain \\ * Correspondence: anaalastruey@isciii.es; Tel.: +34-918223784
}

\section{check for}

updates

Citation: Rivero-Menendez, O.; Soto-Debran, J.C.; Cuenca-Estrella, M.; Alastruey-Izquierdo, A. In Vitro Activity of Ibrexafungerp against a Collection of Clinical Isolates of Aspergillus, Including Cryptic Species and Cyp51A Mutants, Using EUCAST and CLSI Methodologies. J. Fungi 2021, 7, 232. https:// doi.org/10.3390/jof7030232

Academic Editor: David S. Perlin

Received: 16 February 2021

Accepted: 16 March 2021

Published: 20 March 2021

Publisher's Note: MDPI stays neutral with regard to jurisdictional claims in published maps and institutional affiliations.

Copyright: (c) 2021 by the authors. Licensee MDPI, Basel, Switzerland. This article is an open access article distributed under the terms and conditions of the Creative Commons Attribution (CC BY) license (https:// creativecommons.org/licenses/by/ $4.0 /)$.
Abstract: Ibrexafungerp is a new orally-available 1,3- $\beta$-D-glucan synthesis inhibitor in clinical development. Its in vitro activity and that of amphotericin B, voriconazole, and micafungin were evaluated against a collection of 168 clinical isolates of Aspergillus spp., including azole-susceptible and azoleresistant (Cyp51A mutants) Aspergillus fumigatus sensu stricto (s.s.) and cryptic species of Aspergillus belonging to six species complexes showing different patterns of antifungal resistance, using EUCAST and CLSI antifungal susceptibility testing reference methods. Ibrexafungerp displayed low geometric means of minimal effective concentrations (MECs) against A. fumigatus s.s. strains, both azole susceptible $(0.040 \mathrm{mg} / \mathrm{L}$ by EUCAST and CLSI versus $1.231 \mathrm{mg} / \mathrm{L}$ and $0.660 \mathrm{mg} / \mathrm{L}$ for voriconazole, respectively) and azole resistant $(0.092 \mathrm{mg} / \mathrm{L}$ and $0.056 \mathrm{mg} / \mathrm{L}$, EUCAST and CLSI, while those for voriconazole were $2.144 \mathrm{mg} / \mathrm{L}$ and $2.000 \mathrm{mg} / \mathrm{L}$ ). Ibrexafungerp was active against most of the cryptic species of Aspergillus tested, yielding MEC values only comparable to those of micafungin. Nevertheless, this new compound exhibited a moderate activity against $A$. ustus complex species, MECs $\geq 0.5 \mathrm{mg} / \mathrm{L}$ against Aspergillus insuetus and Aspergillus keveii strains, and was inactive against the Aspergillus alliaceus isolates tested $\left(\mathrm{MEC}_{90} \mathrm{~s} \geq 16 \mathrm{mg} / \mathrm{L}\right)$. All in all, ibrexafungerp shows encouraging in vitro results against cryptic species of Aspergillus and azole-susceptible and azole resistant strains of A. fumigatus, some of which are difficult to treat using the available therapeutic options.

Keywords: antifungals; ibrexafungerp; Aspergillus; cyp51A; cryptic; EUCAST; CLSI

\section{Introduction}

Aspergillus species are ubiquitous filamentous fungi that can cause a wide range of infections that are increasing their incidence and threatening the survival of their hosts, especially immunocompromised patients [1]. While Aspergillus fumigatus is responsible for most of the fatal cases of invasive fungal disease, the availability of molecular identification tools has led to the description of cryptic species that had previously been misidentified by classical methods [2]. Closely related cryptic species are gathered in species complexes. Their importance in the clinical setting, in which they have been reported to have a prevalence of up to $19 \%$ in several studies [3-5], and up to $29 \%$ in a recent one [6], is determined by the low susceptibility they generally show against antifungals [3]. The fact that this can lead to poor clinical outcomes [7], together with the toxicity and the interaction with other concomitant medications that these drugs can show [8], evidences the necessity of developing antifungals with new mechanisms of action that help to overcome the limitations of existing clinical drugs.

Ibrexafungerp, formerly SCY-078, is the most representative compound within the triterpenes, a new class of antifungals. This semisynthetic derivative of enfumafungin 
inhibits the fungal $\beta$-(1,3)-D-glucan synthase as echinocandins do, although it is structurally different from those [9] and has an overlapping but independent binding site to the enzyme that generates an alternative drug-enzyme interaction [10]. Its in vitro activity has been successfully assessed against Candida spp., including echinocandin resistant and multidrug-resistant Candida glabrata and Candida auris [11-13], and several Aspergillus species, among which azole or echinocandin resistant $A$. fumigatus isolates stand out, although Aspergillus flavus, Aspergillus niger, and Aspergillus terreus, and a scarce number of Aspergillus glaucus, Aspergillus nidulans, and Aspergillus westerdijkiae strains have also been tested leading to promising results [14-17]. Ibrexafungerp has been reported to display a moderate activity against Scedosporium spp. and Scopulariopsis spp., although it has also been proved to be ineffective against Purpureocillium lilacinum, Fusarium spp. or the Mucorales order [18]. The in vivo activity of this compound has been positively demonstrated when orally or intravenously administered to murine models of invasive candidiasis, invasive aspergillosis, and pneumocystosis [9,14,19-23].

The aim of the present study was to assess the in vitro activity of ibrexafungerp and several antifungal comparators against a collection of Aspergillus clinical isolates, including azole susceptible and resistant $A$. fumigatus s.s. and cryptic species, using antifungal susceptibility by CLSI and EUCAST reference methods. This report constitutes the first one in determining the activity of this new compound against cryptic species of this genus.

\section{Materials and Methods}

A total of 168 Aspergillus strains belonging to six different species complexes were tested: 79 isolates from the Aspergillus fumigatus complex (10 azole-susceptible $A$. fumigatus s.s., 10 azole-resistant $A$. fumigatus s.s. harbouring different mutations in cyp51A gene and in its promoter $\left(4 \mathrm{TR}_{34} / \mathrm{L} 98 \mathrm{H}, 2 \mathrm{TR}_{46} / \mathrm{Y} 121 \mathrm{~F} / \mathrm{T} 289 \mathrm{~A}, 1 \mathrm{G} 54 \mathrm{E}, 1 \mathrm{G} 54 \mathrm{R}, 1 \mathrm{M} 220 \mathrm{I}\right.$, and $\left.1 \mathrm{M} 220 \mathrm{~T}\right)$, 20 Aspergillus lentulus, 10 Aspergillus fumigatiaffinis, 10 Aspergillus thermomutatus, 10 Aspergillus udagawae, 7 Aspergillus hiratsukae, and 2 Aspergillus felis), 18 from the Aspergillus terreus complex (8 Aspergillus citrinoterreus, 4 Aspergillus carneus, 3 Aspergillus aureoterreus, and 3 Aspergillus hortai), 20 from the Aspergillus ustus complex (15 Aspergillus calidoustus, 3 Aspergillus insuetus, and 2 Aspergillus keveii), 15 from the Aspergillus circumdatii complex (10 Aspergillus ochraceus and 5 Aspergillus sclerotiorum), 20 Aspergillus alliaceus from the Aspergillus flavus complex, and 16 Aspergillus tubingensis from the Aspergillus niger complex. All strains were obtained from clinical samples (respiratory, cutaneous, ocular, optical, biopsies, abscesses, blood cultures, and wounds) and identified to species level by standard microscopic morphology and by sequencing the Internal Transcribed Spacer Region of the rDNA as well as part of the $\beta$-tubulin gene, following methods previously reported [24]. The Calmodulin gene was also sequenced for those strains identified as part of the Nigri species complex [25], as it has been reported as the best marker to identify strains belonging to this complex at the species level [26].

Antifungal susceptibility testing was performed following the European Committee on Antimicrobial Susceptibility Testing (EUCAST) reference method 9.3.2 [27] and the Clinical \& Laboratory Standards Institute (CLSI) M38 [28]. The antifungals used were ibrexafungerp (range 0.03-16 mg/L; Scynexis, Inc., Jersey City, NJ, USA), amphotericin B (range 0.03-16 mg/L; Sigma-Aldrich Quimica, Madrid, Spain), voriconazole (range 0.015-8 mg/L; Sigma-Aldrich Quimica, Madrid, Spain), and micafungin (range 0.004-2 mg/L; Astellas Pharma Inc, Tokyo, Japan).

Aspergillus flavus ATCC 204,304 and A. fumigatus ATCC 204,305 were used as quality control strains in all tests performed for both methods. Minimal inhibitory concentrations (MICs) for amphotericin B and voriconazole, and minimal effective concentrations (MECs) for micafungin and ibrexafungerp, were visually read after 24 and $48 \mathrm{~h}$ of incubation at $35^{\circ} \mathrm{C}$ in a humid atmosphere. Geometric mean (GM), $\mathrm{MIC}_{50} / \mathrm{MEC}_{50}$ (MIC/MEC causing inhibition of $50 \%$ of the isolates tested) and $\mathrm{MIC}_{90} / \mathrm{MEC}_{90}$ (MIC/MEC causing inhibition of $90 \%$ of the isolates tested) were determined. For calculation purposes, the MIC or MEC values that exceeded the maximum concentration tested were transformed to the 
next dilution (i.e., if MIC/MEC was $>16 \mathrm{mg} / \mathrm{L}$, it was expressed as $32 \mathrm{mg} / \mathrm{L}$ ) and values that were less than or equal to the minimum concentration tested were transformed to equal (i.e., if MIC/MEC was $\leq 0.03 \mathrm{mg} / \mathrm{L}$, it was expressed as $0.03 \mathrm{mg} / \mathrm{L}$ ). $\mathrm{MIC}_{50} / \mathrm{MEC}_{50}$ and $\mathrm{MIC}_{90} / \mathrm{MEC}_{90}$ were only calculated for species from which five or more isolates were tested.

\section{Results and Discussion}

Table 1 shows the $\mathrm{GM}, \mathrm{MIC}_{50} / \mathrm{MEC}_{50}$, and $\mathrm{MIC}_{90} / \mathrm{MEC}_{90}$, and the ranges for all the species tested for each testing method at $48 \mathrm{~h}$ of incubation. Control strains were within the accepted ranges according to EUCAST and CLSI QC ranges for amphotericin B, voriconazole, and micafungin.

Ibrexafungerp was in vitro active against azole susceptible and resistant $A$. fumigatus s.s. strains. Even though each Cyp51A mutation is linked to a different azole resistance profile [29], ibrexafungerp exhibited encouraging activity against all the Cyp51A mutant strains tested. While $\mathrm{MIC}_{50}$ values for voriconazole were $2 \mathrm{mg} / \mathrm{L}$ by EUCAST and $0.5 \mathrm{mg} / \mathrm{L}$ by CLSI for the susceptible ones and $4 \mathrm{mg} / \mathrm{L}$ by both testing methodologies for the resistant strains, $\mathrm{MEC}_{50} \mathrm{~s}$ for ibrexafungerp were $0.03 \mathrm{mg} / \mathrm{L}$ (EUCAST) and $0.06 \mathrm{mg} / \mathrm{L}$ (CLSI). These results are in agreement with those previously reported after in vitro testing [14-17] and after assessing in vivo activity when administered orally or intravenously in murine models of infection of invasive aspergillosis caused by A. fumigatus [20,22].

All cryptic species from the $A$. fumigatus complex tested showed different resistance profiles against amphotericin $B$ and/or voriconazole, something that has been previously documented [3]. However, ibrexafungerp yielded low MECs (GM values were $\leq 0.227 \mathrm{mg} / \mathrm{L}$ ) only comparable to those from micafungin (GMs $\leq 0.021 \mathrm{mg} / \mathrm{L}$ ) against $\mathrm{As}$ pergillus thermomutatus, Aspergillus udagawae, Aspergillus hiratsukae, and Aspergillus felis, and even against Aspergillus lentulus and Aspergillus fumigatiaffinis, which have been described as resistant to more than one of the available antifungal classes [3].

Species belonging to the Aspergillus terreus complex are characterized for exhibiting low susceptibility to amphotericin B and sometimes moderate susceptibility to azoles [30]. This statement is in line with the MIC values for the strains here tested, which were the highest of those antifungals tested, followed by voriconazole. GM values for ibrexafungerp ranged from $0.030 \mathrm{mg} / \mathrm{L}$ to $0.078 \mathrm{mg} / \mathrm{L}$ against the four species tested by EUCAST and CLSI. Micafungin was also active against them, showing GMs lower than $0.044 \mathrm{mg} / \mathrm{L}$. These values are in agreement with those from previous reports on the in vitro activity of this echinocandin against $A$. terreus complex species [31].

The new drug displayed an intermediate in vitro activity against most of the strains from the Aspergillus ustus complex tested, whose species are known for yielding intrinsically high MICs to most classes of antifungal drugs [32]. While voriconazole was ineffective (MICs $\geq 8 \mathrm{mg} / \mathrm{L}$ ) and micafungin revealed good activity (GM values lower than $0.120 \mathrm{mg} / \mathrm{L}$ ) against them, ibrexafungerp exhibited MEC values (range $0.12-4 \mathrm{mg} / \mathrm{L}$ ) similar to MICs for amphotericin B (range 0.12-2 mg/L). However, the three Aspergillus insuetus strains tested showed higher MECs for this new compound, especially by EUCAST methodology (GM = $3.175 \mathrm{mg} / \mathrm{L}$ versus $1.260 \mathrm{mg} / \mathrm{L}$ by CLSI). Micafungin (GM values of $0.120 \mathrm{mg} / \mathrm{L}$ and $0.095 \mathrm{mg} / \mathrm{L}$ by EUCAST and CLSI, respectively) and even amphotericin B $(\mathrm{GM}=1.000 \mathrm{mg} / \mathrm{L}$ by EUCAST and $0.500 \mathrm{mg} / \mathrm{L}$ by CLSI) revealed a better in vitro activity against these isolates than ibrexafungerp. A higher number of strains from this species should be further evaluated. 


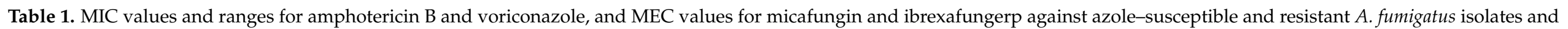
cryptic species of Aspergillus, as determined by the CLSI and EUCAST broth microdilution methods.

Test Method

\begin{tabular}{|c|c|c|c|c|c|c|c|c|c|}
\hline \multirow{4}{*}{$\begin{array}{c}\text { Species (no. tested) } \\
\text { Aspergillus fumigatus complex }\end{array}$} & & \multirow{2}{*}{\multicolumn{8}{|c|}{ Antifungal Test at $48 \mathrm{~h}$ of Incubation by EUCAST and by CLSI }} \\
\hline & & & & & & & & & \\
\hline & & \multicolumn{4}{|c|}{ EUCAST } & \multicolumn{4}{|c|}{ CLSI } \\
\hline & & AMB & VRC & MCF & IBF & $\mathrm{AMB}$ & VRC & $\mathrm{MCF}$ & IBF \\
\hline \multirow[t]{4}{*}{ Aspergillus fumigatus s.s. WT (10) } & $\mathrm{GM}$ & 0.435 & 1.231 & 0.011 & 0.040 & 0.232 & 0.660 & 0.005 & 0.040 \\
\hline & $\mathrm{MIC}_{50} / \mathrm{MEC}_{50}$ & 0.5 & 2 & 0.015 & 0.03 & 0.25 & 0.5 & 0.004 & 0.03 \\
\hline & $\mathrm{MIC}_{90} / \mathrm{MEC}_{90}$ & 0.5 & 2 & 0.03 & 0.12 & 0.25 & 2 & 0.015 & 0.12 \\
\hline & Range & $0.25-0.5$ & $0.5-2$ & $0.004-0.03$ & $0.03-0.12$ & $0.12-0.25$ & $0.25-2$ & $0.004-0.015$ & $0.03-0.12$ \\
\hline \multirow{3}{*}{ Aspergillus fumigatus s.s. azole R (10) } & $\mathrm{MIC}_{50} / \mathrm{MEC}_{50}$ & 0.5 & 4 & 0.015 & 0.06 & 0.12 & 4 & 0.004 & 0.06 \\
\hline & $\mathrm{MIC}_{90} / \mathrm{MEC}_{90}$ & 1 & 16 & 0.03 & 2 & 0.25 & 16 & 0.004 & 0.12 \\
\hline & Range & $0.25-1$ & $0.25-16$ & $0.007-0.06$ & $0.03-8$ & $0.12-0.25$ & $0.25-16$ & $0.004-0.007$ & $0.03-0.12$ \\
\hline \multirow[t]{4}{*}{ Aspergillus lentulus (20) } & GM & 3.864 & 2.639 & 0.009 & 0.086 & 0.636 & 2.378 & 0.004 & 0.074 \\
\hline & $\mathrm{MIC}_{50} / \mathrm{MEC}_{50}$ & 2 & 4 & 0.007 & 0.06 & 0.5 & 2 & 0.004 & 0.06 \\
\hline & $\mathrm{MIC}_{90} / \mathrm{MEC}_{90}$ & 32 & 4 & 0.015 & 0.25 & 1 & 4 & 0.004 & 0.25 \\
\hline & Range & $1-32$ & $0.5-16$ & $0.004-0.03$ & $0.03-0.5$ & $0.12-2$ & $1-4$ & $0.004-0.004$ & $0.03-0.25$ \\
\hline \multirow[t]{3}{*}{ Aspergillus fumigatiaffinis (10) } & $\mathrm{GM}$ & 22.627 & 4.287 & 0.015 & 0.227 & 2.144 & 2.639 & 0.004 & 0.040 \\
\hline & $\mathrm{MIC}_{50} / \mathrm{MEC}_{50}$ & 32 & 4 & 0.015 & 0.12 & 2 & 2 & 0.004 & 0.03 \\
\hline & Range & $8-32$ & $2-8$ & $0.007-0.03$ & $0.03-16$ & $1-8$ & $2-4$ & $0.004-0.004$ & $0.03-0.06$ \\
\hline \multirow{4}{*}{ Aspergillus thermomutatus (10) } & GM & 0.536 & 2.297 & 0.021 & 0.130 & 0.131 & 1.741 & 0.013 & 0.056 \\
\hline & $\mathrm{MIC}_{50} / \mathrm{MEC}_{50}$ & 0.5 & 2 & 0.015 & 0.12 & 0.12 & 2 & 0.015 & 0.06 \\
\hline & $\mathrm{MIC}_{90} / \mathrm{MEC}_{90}$ & 2 & 4 & 0.06 & 0.5 & 0.5 & 4 & 0.06 & 0.12 \\
\hline & Range & $0.25-2$ & $0.5-4$ & $0.015-0.06$ & $0.03-2$ & $0.03-1$ & $0.25-4$ & $0.004-0.06$ & $0.03-0.12$ \\
\hline \multirow[t]{4}{*}{ Aspergillus udagawae (10) } & GM & 3.031 & 2.000 & 0.008 & 0.183 & 0.616 & 1.866 & 0.004 & 0.069 \\
\hline & $\mathrm{MIC}_{50} / \mathrm{MEC}_{50}$ & 2 & 2.000 & 0.007 & 0.12 & 0.5 & 2 & 0.004 & 0.12 \\
\hline & $\mathrm{MIC}_{90} / \mathrm{MEC}_{90}$ & 8 & 4.000 & 0.015 & 8 & 1 & 2 & 0.004 & 0.25 \\
\hline & Range & $2-16$ & $1-4$ & $0.004-0.015$ & $0.03-8$ & $0.5-1$ & $1-2$ & $0.004-0.007$ & $0.03-0.25$ \\
\hline \multirow[t]{4}{*}{ Aspergillus hiratsukae (7) } & GM & 1.641 & 1.811 & 0.008 & 0.221 & 0.301 & 1.641 & 0.005 & 0.042 \\
\hline & $\mathrm{MIC}_{50} / \mathrm{MEC}_{50}$ & 1 & 1 & 0.007 & 0.12 & 0.25 & 2 & 0.004 & 0.06 \\
\hline & $\mathrm{MIC}_{90} / \mathrm{MEC}_{90}$ & 16 & 8 & 0.03 & 8 & 2 & 8 & 0.015 & 0.06 \\
\hline & Range & $0.5-32$ & $0.5-8$ & $0.004-0.03$ & $0.03-16$ & $0.03-2$ & $0.5-8$ & $0.004-0.015$ & $0.03-0.06$ \\
\hline
\end{tabular}


Table 1. Cont.

\begin{tabular}{|c|c|c|c|c|c|c|c|c|c|}
\hline & & \multicolumn{8}{|c|}{ Test Method } \\
\hline & & \multicolumn{8}{|c|}{ Antifungal Test at $48 \mathrm{~h}$ of Incubation by EUCAST and by CLSI } \\
\hline & & & & ST & & & & SI & \\
\hline \multirow[t]{2}{*}{ Aspergillus felis (2) } & GM & 1.414 & 8.000 & 0.007 & 0.085 & 0.707 & 8.000 & 0.004 & 0.060 \\
\hline & Range & $1-2$ & $8-8$ & $0.007-0.007$ & $0.06-0.12$ & $0.5-1$ & $8-8$ & $0.004-0.004$ & $0.06-0.06$ \\
\hline \multicolumn{10}{|l|}{ Aspergillus terreus complex } \\
\hline \multirow[t]{4}{*}{ Aspergillus citrinoterreus (8) } & GM & 3.668 & 0.595 & 0.012 & 0.078 & 1.000 & 0.354 & 0.010 & 0.050 \\
\hline & $\mathrm{MIC}_{50} / \mathrm{MEC}_{50}$ & 4 & 0.5 & 0.015 & 0.06 & 1 & 0.5 & 0.007 & 0.06 \\
\hline & $\mathrm{MIC}_{90} / \mathrm{MEC}_{90}$ & 8 & 1 & 0.015 & 0.12 & 1 & 0.5 & 0.03 & 0.06 \\
\hline & Range & $2-16$ & $0.5-1$ & $0.007-0.015$ & $0.06-0.12$ & $1-1$ & $0.25-0.5$ & $0.007-0.03$ & $0.03-0.06$ \\
\hline \multirow[t]{2}{*}{ Aspergillus carneus (4) } & GM & 1.189 & 1.000 & 0.044 & 0.030 & 0.420 & 1.682 & 0.004 & 0.030 \\
\hline & Range & $1-2$ & $1-1$ & $0.004-4$ & $0.03-0.03$ & $0.25-0.5$ & $1-2$ & $0.004-0.004$ & $0.03-0.03$ \\
\hline \multirow[t]{2}{*}{ Aspergillus aureoterreus (3) } & GM & 2.520 & 0.794 & 0.005 & 0.030 & 0.621 & 0.315 & 0.004 & 0.048 \\
\hline & Range & $0.5-8$ & $0.5-1$ & $0.004-0.007$ & $0.03-0.03$ & $0.12-2$ & $0.25-0.5$ & $0.004-0.004$ & $0.03-0.06$ \\
\hline \multirow[t]{2}{*}{ Aspergillus hortai (3) } & GM & 2.000 & 1.000 & 0.012 & 0.030 & 0.397 & 0.630 & 0.004 & 0.030 \\
\hline & Range & $1-4$ & $1-1$ & $0.007-0.015$ & $0.03-0.03$ & $0.25-0.5$ & $0.5-1$ & $0.004-0.004$ & $0.03-0.03$ \\
\hline \multicolumn{10}{|l|}{ Aspergillus ustus complex } \\
\hline \multirow[t]{2}{*}{ Aspergillus calidoustus (15) } & GM & 0.955 & 8.378 & 0.115 & 0.952 & 0.395 & 8.378 & 0.072 & 0.500 \\
\hline & Range & $0.25-2$ & $4-16$ & $0.06-0.25$ & $0.12-4$ & $0.12-1$ & $8-16$ & $0.03-0.12$ & $0.25-1$ \\
\hline \multirow[t]{2}{*}{ Aspergillus insuetus (3) } & GM & 1.000 & 8.000 & 0.120 & 3.175 & 0.500 & 12.699 & 0.095 & 1.260 \\
\hline & Range & $1-1$ & $8-8$ & $0.12-0.12$ & $2-8$ & $0.5-0.5$ & $8-16$ & $0.06-0.12$ & $0.5-2$ \\
\hline \multirow[t]{2}{*}{ Aspergillus keveii (2) } & GM & 0.707 & 16.000 & 0.085 & 0.707 & 0.354 & 16.000 & 0.030 & 1.000 \\
\hline & Range & $0.5-1$ & $16-16$ & $0.06-0.12$ & $0.5-1$ & $0.25-0.5$ & $16-16$ & $0.03-0.03$ & $0.5-2$ \\
\hline \multicolumn{10}{|l|}{ Aspergillus section Circumdati } \\
\hline \multirow{4}{*}{ Aspergillus ochraceus (10) } & $\mathrm{GM}$ & 10.556 & 0.871 & 0.017 & 0.121 & 1.414 & 0.707 & 0.013 & 0.122 \\
\hline & $\mathrm{MIC}_{50} / \mathrm{MEC}_{50}$ & 32 & 1 & 0.015 & 0.12 & 2 & 1 & 0.015 & 0.12 \\
\hline & $\mathrm{MIC}_{90} / \mathrm{MEC}_{90}$ & 32 & 1 & 0.06 & 0.5 & 2 & 1 & 0.03 & 0.25 \\
\hline & Range & $2-32$ & $0.5-1$ & $0.007-0.06$ & $0.03-1$ & $1-2$ & $0.25-1$ & $0.004-0.03$ & $0.03-0.25$ \\
\hline \multirow[t]{4}{*}{ Aspergillus sclerotiorum (5) } & GM & 16.000 & 2.297 & 0.007 & 0.034 & 2.297 & 1.741 & 0.006 & 0.106 \\
\hline & $\mathrm{MIC}_{50} / \mathrm{MEC}_{50}$ & 32 & 2 & 0.007 & 0.03 & 2 & 2 & 0.004 & 0.12 \\
\hline & $\mathrm{MIC}_{90} / \mathrm{MEC}_{90}$ & 32 & 4 & 0.015 & 0.06 & 4 & 4 & 0.015 & 0.5 \\
\hline & Range & $4-32$ & $1-4$ & $0.004-0.015$ & $0.03-0.06$ & $2-4$ & $1-4$ & $0.004-0.015$ & $0.03-0.5$ \\
\hline
\end{tabular}


Table 1. Cont.

\section{Test Method}

Antifungal Test at $48 \mathrm{~h}$ of Incubation by EUCAST and by CLSI

EUCAST

CLSI

\begin{tabular}{|c|c|c|c|c|c|c|c|c|c|}
\hline \multirow{2}{*}{\multicolumn{10}{|c|}{ Aspergillus flavus complex }} \\
\hline & & & & & & & & & \\
\hline \multirow{4}{*}{ Aspergillus alliaceus (20) } & GM & 28.840 & 0.420 & 0.029 & 5.077 & 17.148 & 0.248 & 0.007 & 1.506 \\
\hline & $\mathrm{MIC}_{50} / \mathrm{MEC}_{50}$ & 32 & 0.5 & 0.03 & 16 & 32 & 0.250 & 0.007 & 1 \\
\hline & $\mathrm{MIC}_{90} / \mathrm{MEC}_{90}$ & 32 & 1 & 0.06 & 32 & 32 & 1 & 0.015 & 16 \\
\hline & Range & $4-32$ & $0.12-1$ & $0.015-0.06$ & $0.03-32$ & $1-32$ & $0.06-1$ & $0.004-0.03$ & $0.12-16$ \\
\hline \multicolumn{10}{|l|}{ Aspergillus niger complex } \\
\hline \multirow{4}{*}{ Aspergillus tubingensis (16) } & GM & 0.249 & 1.044 & 0.010 & 0.065 & 0.089 & 1.682 & 0.007 & 0.053 \\
\hline & $\mathrm{MIC}_{50} / \mathrm{MEC}_{50}$ & 0.25 & 1 & 0.007 & 0.06 & 0.12 & 2 & 0.007 & 0.06 \\
\hline & $\mathrm{MIC}_{90} / \mathrm{MEC}_{90}$ & 0.25 & 2 & 0.03 & 0.12 & 0.12 & 2 & 0.015 & 0.06 \\
\hline & Range & $0.12-0.5$ & $0.5-2$ & $0.007-0.03$ & $0.03-0.12$ & $0.06-0.12$ & $1-2$ & $0.004-0.03$ & $0.03-0.25$ \\
\hline \multirow[t]{4}{*}{ All (168) } & GM & 2.246 & 1.736 & 0.019 & 0.329 & 0.640 & 1.465 & 0.017 & 0.185 \\
\hline & $\mathrm{MIC}_{50} / \mathrm{MEC}_{50}$ & 2 & 2 & 0.015 & 0.12 & 0.5 & 2 & 0.015 & 0.12 \\
\hline & $\mathrm{MIC}_{90} / \mathrm{MEC}_{90}$ & 32 & 8 & 0.12 & 8 & 4 & 8 & 0.06 & 1 \\
\hline & Range & $0.06-32$ & $0.12-16$ & $0.007-4$ & $0.06-32$ & $0.03-32$ & $0.06-16$ & $0.004-0.12$ & $0.03-16$ \\
\hline
\end{tabular}

$\mathrm{AMB}$, amphotericin B; VRC, voriconazole; MCF, micafungin; IBF, ibrexafungerp; s.s., sensu stricto. 
Aspergillus ochraceus and Aspergillus sclerotiorum, which are the most commonly isolated species from section Circumdati from immunosuppressed patients, showed a reduced susceptibility for amphotericin B ( $\mathrm{MIC}_{50}$ of $32 \mathrm{mg} / \mathrm{L}$ ) and were only moderately inhibited by voriconazole ( $\mathrm{MIC}_{90}$ of $1 \mathrm{mg} / \mathrm{L}$ and $2 \mathrm{mg} / \mathrm{L}$ for A. ochraceus by EUCAST and CLSI, respectively, and $4 \mathrm{mg} / \mathrm{L}$ for A. sclerotiorum using both mothodologies), as previously reported [33]. While ibrexafungerp was active against them, with $\mathrm{MEC}_{50}$ values of $0.03-0.12 \mathrm{mg} / \mathrm{L}$, micafungin appeared to be the most effective antifungal in vitro of those tested $\left(\mathrm{MEC}_{50}\right.$ values ranging from $0.004 \mathrm{mg} / \mathrm{L}$ to $\left.0.015 \mathrm{mg} / \mathrm{L}\right)$.

In agreement with previous studies [3,34], Aspergillus alliaceus (flavus complex) and Aspergillus tubingensis (niger complex) show a variable susceptibility against azoles; $A$. alliaceus also yielding elevated MICs against amphotericin B. Ibrexafungerp was mostly inactive against $A$. alliaceus, as $75 \%$ (by EUCAST) and $40 \%$ (by CLSI) of the total number of isolates tested showed MECs $>2 \mathrm{mg} / \mathrm{L}$. When tested in vitro against $A$. flavus strains in previous studies, this new drug did not display a homogenous effectiveness, being reported as active in some studies, with MEC values ranging from $0.06 \mathrm{mg} / \mathrm{L}$ to $0.25 \mathrm{mg} / \mathrm{L}[14,16]$, but as inactive in another (MEC range $2-16 \mathrm{mg} / \mathrm{L}$ ) [15]. Nevertheless, ibrexafungerp exhibited activity against $A$. tubingensis ( $\mathrm{MEC}_{50}$ was $0.006 \mathrm{mg} / \mathrm{L}$ by both methods), although micafungin was the antifungal showing the lowest MECs $\left(\mathrm{MEC}_{50} \mathrm{~s}=0.007 \mathrm{mg} / \mathrm{L}\right)$.

Even though ibrexafungerp was generally active against Aspergillus cryptic species and azole susceptible and resistant $A$. fumigatus s.s. strains, micafungin showed the lowest MEC values against most of the species tested in this study. These results are supported by those obtained in previous works involving in vitro testing of ibrexafungerp and caspofungin against Aspergillus spp. [15,16]. However, ibrexafungerp has a longer half-life and is available as an oral formulation due to its improved pharmacokinetics and pharmacodynamics [35]. In addition to its good in vitro activity against susceptible and azole resistant Aspergillus spp., ibrexafungerp has proven to be effective against a caspofungin resistant A. fumigatus isolate [15] and has also yielded good results in neutropenic mice with invasive aspergillosis caused by azole susceptible and resistant $A$. fumigatus [20,22]. Therefore, this drug is currently undergoing phase II as an oral formulation for the treatment of invasive aspergillosis, as well as being in phase III for the treatment of vulvovaginal and invasive candidiasis. Ibrexafungerp has also been tested in combination with other antifungals against a wide range of fungal pathogens [14], showing synergistic interactions both in vitro and in rabbit models when combined with azoles, especially with isavuconazole, against Aspergillus spp. [22,36].

In this study, CLSI yielded, in general, lower MICs/MECs than EUCAST. These differences were in most cases higher than 2 dilutions for amphotericin B and ibrexafungerp, while voriconazole and micanfungin showed more comparable results. The differences in the size of the inoculum and in the composition of the media in both methodologies could explain these discrepancies [37]. Besides, MECs were difficult to determine for some strains, which led to discrepancies between CLSI and EUCAST methods. This could cause interpretation problems on a routine daily basis and should be further analyzed by performing multicenter studies on the antifungal susceptibility profile of these species.

Given the encouraging in vitro results displayed by ibrexafungerp against Aspergillus spp., and the advantages that this new drug offers in terms of dose administration and improved $\mathrm{PK} / \mathrm{PD}$ characteristics, further research is warranted in order to complete the clinical trial phases for the treatment of invasive aspergillosis, as well as a multicenter study to establish breakpoints and epidemiological cut off values (ECOFFs) for the main clinically important species of this genus. 
Author Contributions: Conceptualization, A.A.-I. and M.C.-E.; methodology, A.A.-I. and M.C.-E.; software, O.R.-M. and A.A.-I.; validation, O.R.-M. and A.A.-I.; formal analysis, O.R.-M., J.C.S.-D., and A.A.-I.; investigation, O.R.-M. and J.C.S.-D.; resources, A.A.-I. and M.C.-E.; data curation, O.R.-M. and A.A.-I.; writing-original draft preparation, O.R.-M.; writing—review and editing, O.R.-M. and A.A.-I.; visualization, O.R.-M. and A.A.-I.; supervision, A.A.-I. and M.C.-E.; project administration, A.A.-I. and M.C.-E.; funding administration, A.A.-I. and M.C.-E.; funding acquisition, A.A.-I. and M.C.-E. All authors have read and agreed to the published version of the manuscript.

Funding: This research was funded by Scynexis, Inc. (Jersey City, NJ, USA). O.R.-M. is supported by a fellowship from the Fondo de Investigación Sanitaria (grant FI14CIII/00025). J.C.S.-D. is supported by a fellowship from the Fondo de Investigación Sanitaria (grant FI17CIII/00027).

Institutional Review Board Statement: Not applicable.

Informed Consent Statement: Not applicable.

Data Availability Statement: Not applicable.

Acknowledgments: These data were previously published as a paper poster in the 28th European Congress of Clinical Microbiology and Infectious Diseases (ECCMID), in Madrid, Spain, 2018. Poster number: P0165. We thank Cristina de Armentia and Teresa Merino for their technical assistance.

Conflicts of Interest: M.C.-E. has received grant support from Astellas, bioMérieux, Gilead Sciences, Merck Sharp \& Dohme, Pfizer, Schering Plough, Soria Melguizo, Ferrer International, CIDARA, F2G, Basilea, Amplyx and Scynexis. A.A.-I. has received honoraria as a speaker in educational talks from Astellas, Gilead Sciences, MSD and Pfizer outside the submitted work. O.R.-M. and J.C.S.-D. declare no conflict of interest. The funders had no role in the design of the study; in the collection, analyses, or interpretation of data; in the writing of the manuscript; or in the decision to publish the results.

\section{References}

1. Kosmidis, C.; Denning, D.W. The clinical spectrum of pulmonary aspergillosis. Thorax 2015, 70, 270-277. [CrossRef] [PubMed]

2. Alastruey-Izquierdo, A.; Mellado, E.; Cuenca-Estrella, M. Current section and species complex concepts in Aspergillus: Recommendations for routine daily practice. Ann. N. Y. Acad. Sci. 2012, 1273, 18-24. [CrossRef] [PubMed]

3. Alastruey-Izquierdo, A.; Alcazar-Fuoli, L.; Cuenca-Estrella, M. Antifungal susceptibility profile of cryptic species of Aspergillus. Mycopahologia 2014, 178, 427-433. [CrossRef]

4. Bongomin, F.; Moore, C.B.; Masania, R.; Rowbotham, E.; Alastruey-Izquierdo, A.; Novak-Frazer, L.; Richardson, M.D. Sequence analysis of isolates of Aspergillus from patients with chronic and allergic aspergillosis reveals a spectrum of cryptic species. Future Microbiol. 2018, 13, 1557-1563. [CrossRef] [PubMed]

5. Negri, C.E.; Gonçalves, S.S.; Xafranski, H.; Bergamasco, M.D.; Aquino, V.R.; Castro, P.T.O.; Colombo, A.L. Cryptic and rare Aspergillus species in Brazil: Prevalence in clinical samples and in vitro susceptibility to triazoles. J. Clin. Microbiol. 2014, 52, 3633-3640. [CrossRef] [PubMed]

6. Salah, H.; Lackner, M.; Houbraken, J.; Theelen, B.; Lass-Flörl, C.; Boekhout, T.; Almaslamani, M.; Taj-Aldeen, S.J. The emergence of rare clinical Aspergillus species in Qatar: Molecular characterization and antifungal susceptibility profiles. Front. Microbiol. 2019, 10, 1677. [CrossRef]

7. Lamoth, F. Aspergillus fumigatus—related species in clinical practice. Front. Microbiol. 2016, 7, 683. [CrossRef]

8. Denning, D.W.; Bromley, M.J. Infectious disease: How to bolster the antifungal pipeline. Science 2015, 347, 1414-1416. [CrossRef]

9. Wring, S.A.; Randolph, R.; Park, S.; Abruzzo, G.; Chen, Q.; Flattery, A.; Garett, G.; Peel, M.; Outcalt, R.; Powell, K.; et al. Preclinical pharmacokinetics and pharmacodynamic target of SCY-078, a first-in-class orally active antifungal glucan synthesis inhibitor, in murine models of disseminated candidiasis. Antimicrob. Agents Chemother. 2017, 61, e02068-16. [CrossRef]

10. Jimenez-Ortigosa, C.; Perez, W.B.; Angulo, D.; Borroto-Esoda, K.; Perlin, D.S. De novo acquisition of resistance to SCY-078 in Candida glabrata involves FKS mutations that both overlap and are distinct from those conferring echinocandin resistance. Antimicrob. Agents Chemother. 2017, 61, e00833-17. [CrossRef]

11. Arendrup, M.C.; Jorgensen, K.M.; Hare, R.K.; Chowdhary, A. In vitro activity of obrexafungerp (SCY-078) against Candida auris isolates as determined by EUCAST methodology and comparison with activity against C. albicans and C. glabrata and with the activities of six comparator agents. Antimicrob. Agents Chemother. 2020, 64, e02136-19. [CrossRef]

12. Pfaller, M.A.; Messer, S.A.; Rhomberg, P.R.; Borroto-Esoda, K.; Castanheira, M. Differential activity of the oral glucan synthase inhibitor SCY-078 against wild-type and echinocandin-resistant strains of Candida species. Antimicrob. Agents Chemother. 2017, 61, e00161-17. [CrossRef] [PubMed]

13. Schell, W.A.; Jones, A.M.; Borroto-Esoda, K.; Alexander, B.D. Antifungal activity of SCY-078 and standard antifungal agents against 178 clinical isolates of resistant and susceptible Candida species. Antimicrob. Agents Chemother. 2017, 61, e01102-17. [CrossRef] [PubMed] 
14. Ghannoum, M.; Long, L.; Larkin, E.L.; Isham, N.; Sherif, R.; Borroto-Esoda, K.; Barat, S.; Angulo, D. Evaluation of the antifungal activity of the novel oral glucan synthase inhibitor SCY-078, singly and in combination, for the treatment of invasive aspergillosis. Antimicrob. Agents Chemother. 2018, 62, e00244-18. [CrossRef] [PubMed]

15. Jimenez-Ortigosa, C.; Paderu, P.; Motyl, M.R.; Perlin, D.S. Enfumafungin derivative MK-3118 shows increased in vitro potency against clinical echinocandin-resistant Candida species and Aspergillus species isolates. Antimicrob. Agents Chemother. 2014, 58, 1248-1251. [CrossRef]

16. Pfaller, M.A.; Messer, S.A.; Motyl, M.R.; Jones, R.N.; Castanheira, M. In vitro activity of a new oral glucan synthase inhibitor (MK-3118) tested against Aspergillus spp. by CLSI and EUCAST broth microdilution methods. Antimicrob. Agents Chemother. 2013, 57, 1065-1068. [CrossRef] [PubMed]

17. Rautemaa-Richardson, R.; Moore, C.B.; Rawson, K.; Novak-Frazer, L.; Angulo, D.; Barat, S.; Richardson, M.D. Aspergillus isolates from patients with chronic pulmonary aspergillosis mycologically and clinically resistant to azole antifungals are sensitive to ibrexafungerp (SCY-078). In Proceedings of the 9th Trends in Medical Mycology, Nice, France, 11-14 October 2019; pp. 11-14.

18. Lamoth, F.; Alexander, B.D. Antifungal activities of SCY-078 (MK-3118) and standard antifungal agents against clinical nonAspergillus mold isolates. Antimicrob. Agents Chemother. 2015, 59, 4308-4311. [CrossRef]

19. Barat, S.; Barroto-Esoda, K.; Ghannoum, M.; Berkow, E.; Angulo, D.A. Activity of ibrexafungerp (formerly SCY-078) against Candida auris: In vitro, in vivo, and clinical case studies of candidemia. Open Forum Infect. Dis. 2019, 6, S307. [CrossRef]

20. Barroto-Esoda, K.; Barat, S.; Angulo, D.; Holden, K.; Warn, P. SCY-078 demonstrates significant antifungal activity in a murine model of invasive aspergillosis. Open Forum Infect. Dis. 2017, 4, S472. [CrossRef]

21. Lepak, A.J.; Marchillo, K.; Andes, D.R. Pharmacodynamic target evaluation of a novel oral glucan synthase inhibitor, SCY-078 (MK-3118), using an in vivo murine invasive candidiasis model. Antimicrob. Agents Chemother. 2015, 59, 1265-1272. [CrossRef]

22. Petraitis, V.; Petraitiene, R.; Katragkou, A.; Maung, B.B.W.; Naing, E.; Kavaliauskas, P.; Barat, S.; Borroto-Esoda, K.; Azie, N.; Angulo, D.; et al. Combination therapy with ibrexafungerp (formerly SCY-078), a first-in-class triterpenoid inhibitor of $(1 \rightarrow 3)$-B-D-glucan synthesis, and isavuconazole for treatment of experimental invasive pulmonary aspergillosis. Antimicrob. Agents Chemother. 2020, 64, e02429-19. [CrossRef]

23. Wiederhold, N.P.; Najvar, L.K.; Jaramillo, R.; Olivo, M.; Pizzini, J.; Catano, G.; Patterson, T.F. Oral glucan synthase inhibitor SCY-078 is effective in an experimental murine model of invasive candidiasis caused by WT and echinocandin-resistant Candida glabrata. J. Antimicrob. Chemother. 2018, 73, 448-451. [CrossRef] [PubMed]

24. Alastruey-Izquierdo, A.; Mellado, E.; Pelaez, T.; Peman, J.; Zapico, S.; Alvarez, M.; Rodríguez-Tudela, J.L.; Cuenca-Estrella, M.; FILPOP Study Group. Population-based survey of filamentous fungi and antifungal resistance in Spain (FILPOP Study). Antimicrob. Agents Chemother. 2013, 57, 3380-3387. [CrossRef]

25. Hong, S.B.; Go, S.J.; Shin, H.D.; Frisvad, J.C.; Samson, R.A. Polyphasic taxonomy of Aspergillus fumigatus and related species. Mycologia 2005, 97, 1316-1329. [CrossRef] [PubMed]

26. Ashtiani, N.M.; Kachuei, R.; Yalfani, R.; Harchegani, A.B.; Nosratabadi, M. Identification of Aspergillus sections Flavi, Nigri, and Fumigati and their differentiation using specific primers. Infez Med. 2017, 2, 127-132.

27. Arendrup, M.C.; Meletiadis, J.; Mouton, J.W.; Lagrou, K.; Hamal, P.; Guinea, J. EUCAST Definitive Document E.DEF 9.3.2: Method for the Determination of Broth Dilution Minimum Inhibitory Concentrations of Antifungal Agents for Conidia Forming Moulds. Available online: https://www.eucast.org/fileadmin/src/media/PDFs /EUCAST_files/AFST/Files/EUCAST_E_Def_9.3.2_ Mould_testing_definitive_revised_2020.pdf. (accessed on 24 September 2020).

28. Clinical and Laboratory Standards Institute (CLSI). Reference Method for Broth Dilution Antifungal Susceptibility Testing of Filamentous Fungi, 3rd ed.; CLSI standard M38; Clinical and Laboratory Standars Institute: Wayne, PA, USA, 2017.

29. Rivero-Menendez, O.; Alastruey-Izquierdo, A.; Mellado, E.; Cuenca-Estrella, M. Triazole resistance in Aspergillus spp.: A worldwide problem? J. Fungi 2016, 2, 21. [CrossRef]

30. Zoran, T.; Sartori, B.; Sappl, L.; Aigner, M.; Sanchez-Reus, F.; Rezusta, A.; Chowdhary, A.; Taj-Aldeen, S.J.; Arendrup, M.C.; Oliveri, S.; et al. Azole-resistance in Aspergillus terreus and related species: An emerging problem or a rare phenomenon? Front. Microbiol. 2018, 9, 516. [CrossRef] [PubMed]

31. Imbert, S.; Normand, A.C.; Ranque, S.; Costa, J.M.; Guitard, J.; Accoceberry, I.; Bonnal, C.; Fekkar, A.; Bourgeois, N.; Houzé, S.; et al. Species identification and in vitro antifungal susceptibility of Aspergillus terreus species complex clinical isolates from a French multicenter study. Antimicrob. Agents Chemother. 2018, 62, e02315-17. [CrossRef]

32. Glampedakis, E.; Cassaing, S.; Fekkar, A.; Dannaoui, E.; Bougnoux, M.E.; Bretagne, S.; Neofytos, D.; Schreiber, P.W.; Hennequin, C.; Morio, F.; et al. Invasive aspergillosis due to Aspergillus section Usti: A multicenter retrospective study. Clin. Infect. Dis. 2020, ciaa230. [CrossRef]

33. Siqueira, J.P.; Sutton, D.A.; Gene, J.; Garcia, D.; Wiederhold, N.; Peterson, S.W.; Guarro, J. Multilocus phylogeny and antifungal susceptibility of Aspergillus section Circumdati from clinical samples and description of A. pseudosclerotiorum sp. nov. J. Clin. Microbiol. 2017, 55, 947-958. [CrossRef]

34. Perez-Cantero, A.; Lopez-Fernandez, L.; Guarro, J.; Capilla, J. New insights into the Cyp51 contribution to azole resistance in Aspergillus section Nigri. Antimicrob. Agents Chemother. 2019, 63, e00543-19. [CrossRef] [PubMed]

35. Davis, M.R.; Donnelley, M.A.; Thompson, G.R. Ibrexafungerp: A novel oral glucan synthase inhibitor. Med. Mycol. 2020, 58, 579-592. [CrossRef] [PubMed] 
36. Jagadeesan, V.; Driscoll, E.; Hao, B.; Barat, S.; Borroto-Esoda, K.; Angulo, D.; Clancy, C.; Nguyen, M. In vitro evaluation of combination of ibrexafungerp and azoles against Aspergillus spp. isolated from lung transplant recipients. In Proceedings of the 9th Advances Against Aspergillosis and Mucormycosis, Lugano, Switzerland, 27-29 February 2020; Volume 89.

37. Alastruey-Izquierdo, A.; Melhem, M.S.; Bonfietti, L.X.; Rodriguez-Tudela, J.L. Susceptibility test for fungi: Clinical and laboratorial correlations in medical mycology. Rev. Inst. Med. Trop Sao Paulo 2015, 57, 57-64. [CrossRef] [PubMed] 